\title{
REKOMENDASI TATA KELOLA ASET TI BERDASARKAN COBIT 5
}

\author{
Hendrik Kusbandono \\ Jurusan Teknik, Program Studi Teknologi Informasi \\ Politeknik Negeri Madiun \\ Email: h3ndrik57@pnm.ac.id \\ Dwiyono Ariyadi \\ Fakultas Teknik, Teknik Informatika \\ Universitas Muhammadiyah Ponorogo \\ Email: dwiyono_ariyadi@umpo.ac.id
}

\begin{abstract}
ABSTRAK
Layanan akademik berbasis teknologi informasi (TI) internal sekolah SMK memerlukan sarana pendukung berupa software dan hardware. Ketersediaan sarana aset TI ini akan berpengaruh pada keberlangsungan kegiatan proses bisnis di sekolah. Investasi prasarana aset TI diperlukan biaya yang tidak hanya sedikit. Pengelolaan aset TI yang maksimal akan memberikan nilai optimal pada keberlangsungan layanan TI, hal ini akan berdampak pada pencapaian tujuan organisasi. Diperlukan tata kelola TI yang dapat memberi nilai optimal terhadap penggunaan TI. Penelitian ini menggunakan framework COBIT 5 subdomain BAI09 dengan analisis tingkat kematangan menggunakan model PAM. Hasil dari penelitian ini adalah mengetahui kondisi tingkat kapabilitas saat ini di SMK Kabupaten Madiun, yaitu rata-rata activity pada subdomain BAI09 berada pada level Performed Process. Target tingkat kapabilitas yang diharapkan hingga tiga tahun kedepan yaitu pada level established process. Rekomendasi perbaikan dibuat bertahap sesuai acuan COBIT 5.
\end{abstract}

Kata kunci: tata kelola; aset ti; cobit 5.

\begin{abstract}
Academic services-based information technology (IT) internal school SMK requires a means of supporting the form of software and hardware. This means the IT asset availability will affect the sustainability of the business process activities in school. The IT asset infrastructure required investment cost that is not just a little. The IT asset management that will give the maximum value of the optimal continuity of it services, this will have an impact on the achievement of the objectives of the organization. Necessary it governance that can provide the optimum value of the use of IT. This research uses the framework COBIT 5 subdomains BAI09 with an analysis of the level of maturity using the PAM model. The result of this research is to know the condition of the level of current capabilities in Madiun Regency, namely SMK average activity on the subdomain BAIO9 is Performed at level Process. The target level of the expected capabilities of up to three years i.e. on the level established process. Gradual improvement made recommendations accordingly reference COBIT 5.
\end{abstract}

Keywords: governance; assets it; cobit 5.

\section{PENDAHULUAN}

Instansi sekolah SMA/SMK dalam memenuhi layanan pendidikan perlu berbagai sarana pendukung. Salah satu di antaranya sarana pelayanan informasi administrasi berbasis Teknologi Informasi (TI) di lingkup internal sekolah sendiri, maupun yang berhubungan dengan pihak dinas pendidikan provinsi. Layanan informasi berbasis TI di lingkup internal sekolah umumnya meliputi hardware dan software pendukung kegiatan akademik. Untuk layanan informasi berbasis TI ini pihak sekolah telah berinvestasi cukup besar untuk pengadaan dan pengelolaan aset TI. Aset TI berupa perangkat keras dan perangkat lunak harus dipertanggungjawabkan, dioptimalkan dan dijamin untuk memberikan nilai dukungan terhadap ketercapaian tujuan instansi. Pengelolaan aset TI memiliki peran penting dalam hal tata kelola IT instansi[1]. Manajemen pengelolaan aset di sekolah yang dilakukan selama ini sebagian besar masih terbatas pada pencatatan atau identifikasi aset, hal ini terjadi disebabkan oleh keterbatasan pengetahuan pengelola aset sekolah. Dengan pengelolaan seperti ini, prasarana aset TI belum dapat memiliki nilai optimal dalam peran sebagai pendukung ketercapaian tujuan organisasi. 
Kondisi yang terjadi di SMK ini tidak boleh diabaikan terlalu lama, karena dengan perlakuan yang demikian nilai aset TI belum bisa memberikan nilai kontribusi yang besar terhadap tujuan instansi. Untuk mengetahui kondisi yang terjadi saat ini serta target apa yang diinginkan oleh instansi, maka bisa dilakukan kegiatan audit sistem informasi terhadap pengelolaan aset TI.

Tujuan audit sistem informasi adalah pengamanan aset, efektifitas sistem, efisiensi sistem, ketersediaan, kerahasiaan, kehandalan, dan menjaga integritas data [2]. Sedangkan aset informasi pada orgasisasi seperti hardware, software, sumber daya manusia, data, dan fasilitas lain yang harus dijaga dengan baik, agar tidak terjadi penyalahgunaan terhadap aset organisasi [3]. Sebagai aset penting dengan nilai investasi, dan resiko yang tinggi, TI harus didukung tata kelola yang baik dalam rangka mencapai tujuan organisasi [4]. Investasi pengadaan TI yang telah dilakukan pihak sekolah, sebaiknya dilakukan evaluasi tata kelola pengelolaan aset TI untuk menyelaraskan sesuai dengan tujuan organisasi. COBIT merupakan salah satu framework yang dapat digunakan oleh auditor TI sebagai alat yang komprehensif untuk menciptakan tata kelola TI pada suatu organisasi [3].

Penelitian sebelumnya adalah Dewi (2017) menggunakan COBIT 4.1 untuk melakukan evaluasi pada administrasi pelayanan publik aplikasi kependudukan SIAK kota Denpasar. Subdomain yang dipilih adalah AI3. Hasil yang diperoleh pada proses AI3 (mendapatkan dan memelihara infrastruktur teknologi) yaitu berada pada level 3 (defined) [5].

Octaviyanti (2018) menggunakan COBIT 5 untuk mengaudit pada sistem enterprise aset management EAM di PT Mitrabara Adiperdana Tbk dan PT Baradinamika Mudasukses. Penelitian ini bertujuan mengetahui tingkat kapabilitas pada subdomain EDM02 (kontribusi nilai bisnis perusahaan), BAI06 (mengelola perubahan dengan terkendali) dan BAI09 (mengelola aset TI perusahaan). Rata-rata tingkat kapabilitas yang diperoleh berada di level 3. Hasil penelitian ini berupa rekomendasi pengelolaan perubahan dan pengelolaan aset [6].

Penelitian ini bertujuan untuk mengetahui kondisi saat ini tata kelola TI pada pengelolaan aset TI, serta tingkat kapabilitas tata kelola TI yang diharapkan nantinya. Untuk menilai tingkat kapabilitas saat ini (as-is) dan harapan (tobe) framework yang digunakan adalah COBIT 5. Pada COBIT 5 tingkat kapabilitas meliputi 5 level yaitu mulai dari level 0 incomplete process, level 1 performed process, level 2 managed process, level 3 established process, level 4 predictable process, level 5 optimising process.

\section{METODOLOGI PENELITIAN}

Metode deskriptif kualitatif yang digunakan pada analisis penelitian ini dengan cara menyebarkan kuisioner kepada responden. Kuisioner berisi pertanyaan-pertanyaan yang mengacu tata kelola TI COBIT 5 khususnya domain yang sesuai dengan permasalahan.

\subsection{Metode Pengumpulan Data}

Adapun kegiatan dalam pengumpulan data meliputi :

a. Observasi

Mengamati kegiatan di beberapa sekolah SMK di Kabupaten Madiun sebagai tujuan obyek penelitian, pengamatan difokuskan pada prasarana TI dengan harapan dapat mendapatkan gambaran permasalahan serta tujuan penelitian.

b. Kuisioner

Metode kuisioner dilakukan sebagai bahan pengumpulan data, kuisioner ditujukan ke responden beberapa sekolah SMK Kabupaten Madiun, adapun yang menjadi responde adalah pengelola TI di masing-masing sekolah.

c. Wawancara

Wawancara dilakukan untuk mendukung data yang mungkin belum termuat dalam kuisioner.

\subsection{Metode Analisis Data}

Adapun analisis dilakukan dalam tiga tahapan, yaitu :

a. Penilaian Tingkat Kapabilitas

Dihitung tingkat kapabilitas dari activity dari analisis hasil kusioner subdomain terpilih. Analisis tingkat kapabilitas untuk menilai kondisi saat ini (as-is) tatakelola APO09, serta menilai tingkat kapabilitas harapan (tobe). COBIT menyediakan tingkat kapabilitas level 0 - 5. Langkah penghitungan indeks tingkat kapabilitas dengan cara total jawaban responden dikalikan nilai bobot dan dibagi jumlah responden, seperti pada rumus persamaan (1) 


$$
\text { indeks tingkat kapabilitas }=\frac{\Sigma(\text { total jawaban } x \text { bobot })}{\text { jumlah responden }}
$$

b. Analisis Kesenjangan/Gap

Tahapan analisis kesenjangan tingkat kapabilitas saat ini (as-is) dengan tingkat kapabilitas yang diharapkan (to be).

c. Penyusunan rekomendasi

Penyusunan rekomendasi berdasarkan nilai analisis kesenjangan dan mengacu procces assesment model (PAM) dan ISO 15504-2, 2003.

\section{HASIL DAN PEMBAHASAN}

\subsection{Analisis Tingkat Kapablitas}

Berdasarkan data rekapituasi, diperoleh tingkat kapabilitas pada masing-masing activity, kondisi saat ini secara rata-rata subdomain pengelolaan aset TI proses BAI09 masih berada pada level 1 Performed Process.

Tabel 1. Rekapitulasi tingkat kapabilitas

\begin{tabular}{llc}
\hline $\begin{array}{c}\text { Sub domain } \\
\text { (activity) }\end{array}$ & $\begin{array}{c}\text { Procces } \\
\text { attribut }\end{array}$ & $\begin{array}{c}\text { Level } \\
\text { kapabilitas }\end{array}$ \\
\hline BAI09.1 & $2.2(\mathrm{~L})$ & 2 \\
BAI09.2 & $2,1(\mathrm{P})$ & 1 \\
BAI09.3 & $2,1(\mathrm{P})$ & 1 \\
BAI09.4 & $2,1(\mathrm{P})$ & 1 \\
BAI09.5 & $2.1(\mathrm{P})$ & 1 \\
\hline Rata-rata & & 1,2 \\
\hline
\end{tabular}

Catatan:

F : fully achieved

$L \quad$ : Largely achieved

$P \quad$ : Partially achieved

Mengacu pada Tabel 1 rekapitulasi tingkat kapabilitas, kondisi kemampuan saat ini pada subdomain BAI09 dideskripsikan sebagai berikut:

a. BAI09.01 (Identify and record current assets)

Aktivitas atribut ini ada di level 2.2 skala largely achieved $(L)$. Karena masih berda di skala L, maka level kapabilitas sudah di level 2. Dimana pihak SMK telah melakukan kegiatan pengidentifikasian secara manual atau komputerisasi untuk prasarana hardware, software dan pendukung TI. Termasuk juga kegiatan monitoring terkait aset TI.

b. BAI09.02 (Manage cricital assets)

Aktivitas atribut ini ada di level 2.1 skala partially achieved (P). Karena masih berda di skala P, maka level kapabilitas pada level 1. Terbukti telah melakukan kegiatan pengidentifikasian aset TI yang dianggap penting atau vital seperti pengidentifikasian server, sarana jaringan LAN dan internet, serta software yang dianggap penting.

c. BAI09.03 (Manage the asset life cycle)

Atribut ini ada di level 2.1 skala partially achieved (P). Karena masih berada pada skala P maka level kapabilitas pada activity termasuk di level 1. Aktivitasnya yang sudah dilakukan diantaranya pengidentifikasian aset TI yang rusak, aset yang masih dapat diperbaiki kembali, atau pemusnahan aset yang sudah tidak terpakai.

d. BAI09.04 (Optimise asset costs)

Atribut ini ada di level 2.1 skala partially achieved (P). Karena di skala P maka level kapabilitas adalah level 1. Aktivitas pada atribut ini terbukti pihak manajemen sekolah telah melakukan kegiatan peninjauan asset TI yang masih mampu dipakaiuntuk support pengoptimalan pemetaan anggaran prasarana sekolah. 
e. BAI09.05 (Management License)

Atribut ini ada di level 2.1 skala P. Karena di skala P maka level maka level kapabilitas proses ini adalah level 1 Performed Process. Bukti aktivitasnya meliputi masih sebagian kecil instansi yang sadar akan menggunakan perangkat lunak berlisensi.

\subsection{Analisis Gap}

Kondisi harapan atau target kapabilitas manajemen aset TI pada SMK Madiun merupakan acuan arah tata kelola TI yang akan dikembangkan. Target harapan tingkat kapabilitas dapat ditentukan dari lingkungan internal instansi. Dari hasil wawancara dengan pihak manajemen sekolah mereka mentargetkan harapan tata kelola manajemen aset TI kurun waktu tiga tahun kedepan berada pada level 3 .

Rekomendasi perbaikan tatakelola TI mengacu pada model process assesment model (PAM) dan ISO 15504-2, 2003, perbaikan dilakukan secara bertahap, dilakukan satu tingkat diatasnya jika proses attribut (PA) sudah pada kondisi largely achieved (L) atau fully achieved $(F)$.

Perbaikan belum dapat dilakukan jika masih berada pada level dibawahnya yaitu jika masih pada level not achieved $(N)$ atau partially achieved $(P)$. Analisis gap tingkat kapabilitas disajikan pada Gambar 1.

\section{Diagram radar gap tingkat kapabilitas}

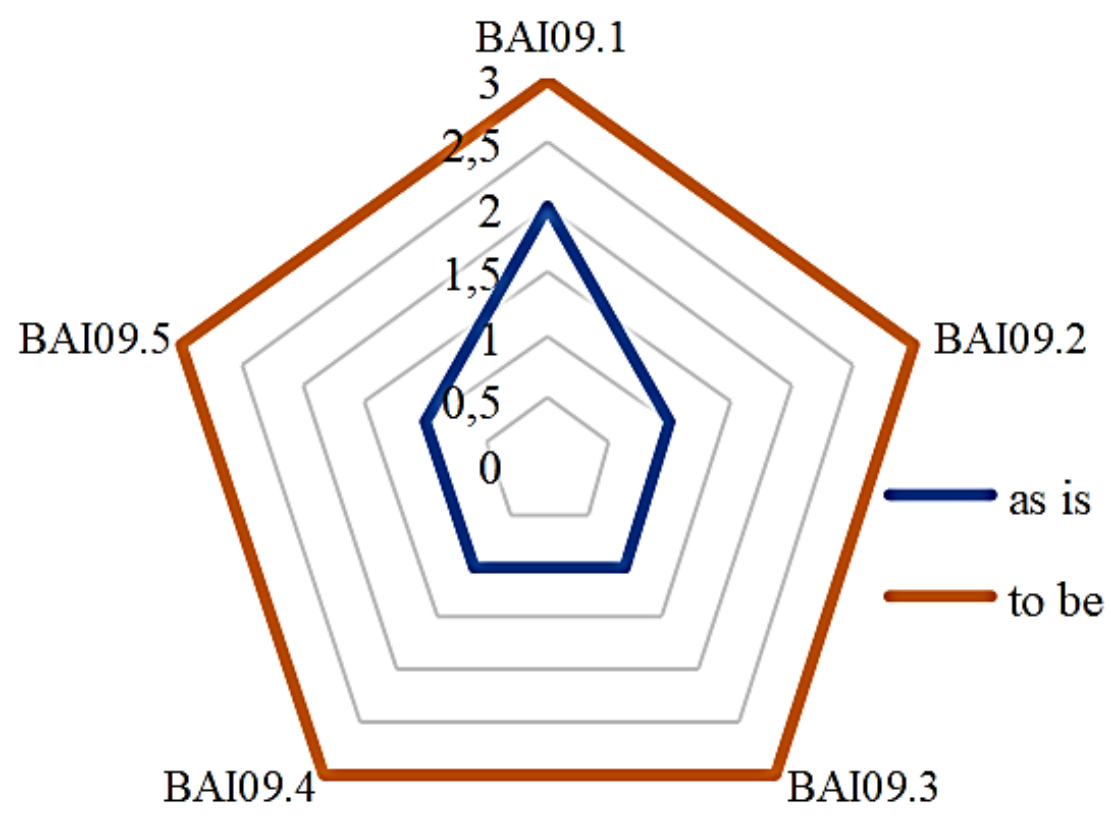

Gambar 1. Diagram Radar Gap Tingkat Kapabilitas

Mengacu Gambar 1 diagram radar gap tingkat kapabilitas maka diperlukan perbaikan bertahap pada tata kelola manajemen aset TI di SMK Madiun. Skenario perbaikan pada subdomain BAI09 manajemen pengelolaan aset TI direncanakan sebagai berikut :

a. BAI09.01 (Identify and record current assets)

Diperlukan pendokumentasian seluruh aset TI secara detail termasuk status kondisi keadaan aset. Dilanjutkan tahap monitoring secara berkala (target pelaksanaan tahun ke 1). Adanya prosedur dalam pengadaan aset TI yang selaras dengan kebutuhan instansi. (target pelaksanaan tahun ke 2).

b. BAI09.02 (Manage cricital assets)

Dibuatnya prosedur kebijakan khusus pengelolaan aset TI yang dianggap penting, karena menyangkut keberlangsungan proses bisnis instansi. Dilanjutkan tahap monitoring keberlangsungan pelaksanaan prosedur yang telah dibuat (target pelaksanaan tahun ke 2). Adanya monitoring memastikan ketersediaan aset TI yang dianggap penting atau vital (target pelaksanaan tahun ke 2). 
c. BAI09.03 (Manage the asset life cycle)

Dibuatnya SOP pemusnahan aset TI yang rusak. Dilanjutkan tahap monitoring pelaksanaan SOP tersebut (target pelaksanaan tahun ke 1). Perencaan pembuatan prosedur pemilahan aset TI yang kondisi masih layak namun tidak terpakai untuk dihibahkan ke pihak lain. Dilanjutkan tahap monitoring pelaksanaanya (target pelaksanaan tahun ke 3).

d. BAI09.04 (Optimise asset costs)

Untuk mengoptimalkan anggaran prasarana TI, proses pengadaan aset TI harus mengacu pada kebermanfaat dan nilai guna yang mendukung tujuan sekolah. Dilanjutkan monitoring SOP pada tahapan pengadaan prasarana TI. (target pelaksanaan tahun ke 2).

e. BAI09.05 (Management License)

Pembuatan prosedur terkait melisensikan software yang penting secara berkala. Dilanjutkan memonitoring pelaksana lisensi software (target pelaksanaan tahun ke 3).

Ringkasan skenario perbaikan secara bertahap dalam kurun waktu tiga tahun pada masing-masing subdomain disajikan di tabel 2.

Tabel 2. Skenario perbaikan bertahap

\begin{tabular}{ccccc}
\hline Sub domain & Level & \multicolumn{3}{c}{ Level tobe } \\
\cline { 3 - 5 } (activity) & as-is & Tahun ke1 & Tahun $\boldsymbol{k e 2}$ & Tahun ke3 \\
\hline BAI09.1 & 2 & Level 3 & Level 3 & \\
BAI09.2 & 1 & & Level 2-3 & \\
BAI09.3 & 1 & & Level 2 & Level 3 \\
BAI09.4 & 1 & & Level 2-3 & \\
BAI09.5 & 1 & & Level 2 & Level 3 \\
\hline
\end{tabular}

\section{KESIMPULAN}

Kesimpulan dari penelitian yang telah dilakukan pada tata kelola manajemen aset TI SMK Madiun dengan menggunakan framework COBIT 5 menyatakan, kondisi kemampuan saat ini proses BAI09 yang meliputi BAI09.1 sudah berada pada level 2 managed process, dimana pihak sekolah sejauh ini telah melakukan kegiatan identifikasi terhadap aset TI yang meliputi prasarana hardware, software dan pendukung TI, kegiatan tersebut ditindaklanjuti dengan monitoring. Sedangkan empat activity yang berikutnya yaitu BAI09.2, BAI09.3, BAI09.4 dan BAI09.5 masih pada level 1 Performed Process. Kegiatan pada level ini digambarkan telah ada kegiatan pencatatan inventarisasi aset penting, aset yang rusak, peninjauan aset TI yang bisa diperbaiki, serta sebagian kecil software yang berlisensi. Namun semua kegiatan tersebut masih sebagian kecil yang ditindak lanjuti hingga tahapan monitoring.

Target dari pihak sekolah dalam meningkatkan tingkat kapabilitas kepatuhan tata kelola manajemen aset TI direncanakan hingga tiga tahun kedepan yaitu pada level 3 established process. Untuk mencapai level ketiga tersebut diperlukan keseriusan pihak sekolah dalam memperbaiki tatakelola manajemen aset TI. Pihak peneliti merekomendasikan perbaikan secara bertahap tiap tahunnya, skenario perbaikan dibuat bertahap agar jelas target capaian tiap tahunnya.

\section{DAFTAR PUSTAKA}

[1] S. Wardani and M. Puspitasari, "Audit Tata Kelola Teknologi Informasi Mengunakan Framework Cobit Dengan Model Maturity Level ( Studi Kasus Fakultas Abc ),” J. Teknol., vol. 7, no. 1, pp. 3846, 2014.

[2] Sanyoto Gondodiyoto, Audit Sistem Informasi (+ Pendekatan CobIT). Mitra Wacana Media, 2007.

[3] M. Johanes Fernandes Andry, S.T., M.Kom,, Kevin Christianto, S.Kom., AUDIT MENGGUNAKAN COBIT 4.1 DAN COBIT 5 DENGAN CASE STUDY. Teknosain, 2017.

[4] R. E. Putri, "Model Penilaian Kapabilitas Proses Optimasi Resiko Ti Berdasarkan Cobit 5," Semin. Nas. Inform. 2015, vol. 2015, no. November, pp. 252-258, 2015.

[5] I. M. O. Widyantara, “Audit Infrastruktur Aplikasi Pelayanan Publik Pemerintah Kota Denpasar," vol. 16, no. 02, pp. 78-83, 2017. 
Jurnal SIMETRIS, Vol. 9 No. 2 November 2018

P-ISSN: 2252-4983, E-ISSN: 2549-3108

[6] P. Octaviyanti and J. F. Andry, "Audit Sistem Enterprise Asset Management Menggunakan Framework Cobit 5," Ikraith-Informatika, vol. 2, no. 2, pp. 34-42, 2018. 